\title{
Morpho-agronomic Classification of Some Native and Exotic Finger Millet (Eleusine coracana L.) Germplasm Accessions in Ethiopia
}

\author{
Chemeda Daba ${ }^{1}$ and Gemechu Keneni2 ${ }^{*}$ \\ ${ }^{1}$ Bako Agricultural Research Center, P O Box 03, West Shewa, Ethiopia \\ ${ }^{2}$ Holetta Agricultural Research Center, P O Box 2003, Addis Ababa, Ethiopia
}

\begin{abstract}
Finger millet (Eleusine coracana L.) is one of the important indigenous crops of Africa. The productivity of the crop, however, is very low owing to several factors including the inherent low-yielding potential of the cultivars. Information on genetic diversity among the available germplasm collections is very useful for breeding programs utilizing the materials as germplasm source. An experiment was conducted at Arsi Negele and Bako, Ethiopia, in 2000 main season to study the extent of genetic variability present among sixty-four germplasm accessions collected from the Eastern and Southern Africa and maintained at the Institute of Biodiversity Conservation, Ethiopia. The accessions were planted in three replications at both locations using a randomized complete block design. Data were recorded on eleven morpho-agronomic characters. Analysis of variance at both locations showed that the mean squares due to genotype and genotype by location interaction were significant $(\mathrm{P}$ $\leq 0.05)$ in almost all the cases. Broad-sense heritability values at each location and combined over locations were higher $(>80 \%)$ for most of the characters, indicating the existence of a wealth of genetic variability among the population for most of the morpho-agronomic traits. Cluster analysis grouped the accessions into four clusters of different sizes. It appears that geographical origin has no or little effect in determining the pattern of genetic diversity observed among the accessions. The greatest variability among accessions was observed for characters such as biomass, ear weight and grain weight, which highly dictated the differentiation of accessions into clusters. Genetic distances between cluster IV and all other clusters were significant indicating that crosses between selection from members of cluster IV with the rest of the clusters may provide desirable recombinant in breeding efforts. Parental selection should also be based on the existence of optimum level of the desired traits.
\end{abstract}

Keywords: Eleusine coracana; Germplasm Collections; Genetic Diversity; Geographic Origin

\section{Introduction}

Finger millet (Eleusine coracana (L.) Gaertn), probably originated from Eleusine coracana spp. Africana, is native to Ethiopia (Dogget, 1986). East Africa in general and Ethiopia in particular are now considered as center of origin and diversity for finger millet (FAO, 1998). The crop is grown as stable food grain in tropical and subtropical Africa and Asia providing cheap source of protein, mineral and vitamin (Pulseglove, 1988). In Ethiopia, finger millet is mainly produced in the northern and western parts of the country (Yilma and Abebe, 1986). The crop is annually grown on about 228000 ha of land contributing 1.5 million metric tones to annual grain production (Tadessie et al., 1995).

Genetic variability among germplasm collections is an essential pre-requisite for effective plant breeding. This is because chances of identifying superior segregants is higher among populations developed from crosses involving parents of diverse genetic background than those coming from common or closely related backgrounds (Singh, 1990). Although large number of millet germplasm accessions have been collected and preserved at the Institute of Biodiversity Conservation, Ethiopia, little information is available on genetic structure of the accessions. Therefore, information on the extent and pattern of genetic diversity present among the accessions is very important for genetic improvement of the crop. This experiment was an attempt to determine the extent of genetic variability present among the local finger millet germplasm collections as well as some germplasm sources of exotic origin.

\section{Materials and Methods}

A total of 64 finger millet accessions including 46 local landraces and 17 introductions were studied along with a standard check variety. All test entries were obtained from the Institute of Biodiversity Conservation, Addis Ababa. The local landraces were collected from Gojam, Gonder, Wellega, Gamogofa, Ilubabor, Hararge, Shewa and Sidamo regions of Ethiopia whereas all of the introductions except one come from Zimbabwe. The list of germplasm accessions along with some of the passport information is given in Table 1.

The field experiments were carried out at Arsi Negele, a sub-station of Melkassa Agricultural Research Center, and Bako Agricultural Research Center during 2000 main season. Arsi Negele located at 1960 meters above sea level represent highland test environments whereas Bako with only 1650 meters elevation represents typical lowland test environments. The experiment was laid in a randomized complete block design with 3 replications. A single row plot of $5 \mathrm{~m}$ length was used to evaluate the accessions with between plot distance of $0.75 \mathrm{~m}$. Seeds were drilled into a row and latter thinned to $15 \mathrm{~cm}$ distance between plants. All other crop management practices were undertaken following research recommendations specific to each location. For data collection five plants were randomly selected from each plot and marked with a label. Data were recorded on plant height $(\mathrm{cm})$, number of Productive tillers per plant, ear length $(\mathrm{cm})$, number of fingers per main ear, ear weight per plant $(\mathrm{g})$, biomass weight per plant $(\mathrm{g})$, grain weight per plant $(\mathrm{g})$, thousand seed weight $(\mathrm{g})$ and harvest index. The mean value of five plants measured from each plot represented plot data for the above traits. Data on days to flowering and maturity, however, were recorded on a plot basis. 
Table 1. Description of the tested germplasm collections.

\begin{tabular}{|c|c|c|c|c|c|}
\hline Sr. No. & Accession & Origin & Altitude (m. a. s. l) & Head type & Seed color \\
\hline 1 & 203260 & Zimbabwe & 1100 & Close & Red \\
\hline 2 & 100014 & Ethiopia (Gojam) & 2000 & Open & Red \\
\hline 3 & 100010 & Ethiopia (Hararge) & 1830 & Close & White \\
\hline 4 & 100006 & Ethiopia (Shewa) & 1670 & Open & Red \\
\hline 5 & 203303 & Zimbabwe & $\mathrm{Na}^{\mathrm{a}}$ & Close & Red \\
\hline 6 & 100058 & Ethiopia (Gamo-Gofa) & $\mathrm{Na}$ & Close & Red \\
\hline 7 & 100043 & Ethiopia (Gojam) & 2040 & Open & Dark \\
\hline 8 & 203057 & Ethiopia (Illubabor) & 1850 & Close & Red \\
\hline 9 & 100057 & Ethiopia (Gamo-Gofa) & 1460 & Open & Brown \\
\hline 10 & 203264 & Zimbabwe & 900 & Close & Red \\
\hline 11 & 203289 & Zimbabwe & 850 & Close & Red \\
\hline 12 & 100019 & Ethiopia (Gonder) & 2240 & Open & Red \\
\hline 13 & 2203058 & Ethiopia (Illubabor) & 1840 & Close & Red \\
\hline 14 & 203060 & Ethiopia (Illubabor) & 1850 & Close & Brown \\
\hline 15 & 100064 & Ethiopia (Wellega) & 1440 & Close & Red \\
\hline 16 & 203259 & Zimbabwe & 1100 & Close & Red \\
\hline 17 & 203265 & Zimbabwe & 900 & Close & Red \\
\hline 18 & 203288 & Zimbabwe & 720 & Close & Red \\
\hline 19 & 100009 & Ethiopia (Hararge) & 2010 & Close & White \\
\hline 20 & 203246 & Zimbabwe & 1487 & Close & Red \\
\hline 21 & 203309 & Zimbabwe & 750 & Close & Red \\
\hline 22 & 203251 & Zimbabwe & 1150 & Close & White \\
\hline 23 & 203300 & Zimbabwe & $\mathrm{Na}$ & Close & Red \\
\hline 24 & 203319 & Zimbabwe & 980 & Close & Red \\
\hline 25 & 203260 & Zimbabwe & 1110 & Close & White \\
\hline 26 & 203258 & Zimbabwe & 1180 & Close & Red \\
\hline 27 & 100059 & Ethiopia (Gamo-Gofa) & $\mathrm{Na}$ & Close & Brown \\
\hline 28 & 100015 & Ethiopia (Gojam) & 1780 & Open & Red \\
\hline 29 & 203391 & Zimbabwe & 1440 & Close & Red \\
\hline 30 & 100050 & Ethiopia (Gojam) & 2250 & Open & Brown \\
\hline 31 & 100016 & Ethiopia (Gojam) & 1800 & Open & Red \\
\hline 32 & 203278 & Zimbabwe & 740 & Close & Red \\
\hline 33 & 100008 & Ethiopia (Sidamo) & $\mathrm{Na}$ & Open & Red \\
\hline 34 & 100004 & Ethiopia (Gonder) & $\mathrm{Na}$ & Open & Brown \\
\hline 35 & 203061 & Ethiopia (Wellega) & 1630 & Close & Red \\
\hline 36 & 203249 & Zimbabwe & 1450 & Open & Red \\
\hline 37 & 212692 & Ethiopia (Gojam) & 2340 & Open & White \\
\hline 38 & 205837 & Ethiopia (Gojam) & 2050 & Open & White \\
\hline 39 & 205838 & Ethiopia (Gojam) & 2070 & Open & White \\
\hline 40 & 215839 & Ethiopia (Gojam) & 2050 & Open & White \\
\hline 41 & 215841 & Ethiopia (Gojam) & 2050 & Open & White \\
\hline 42 & 215842 & Ethiopia (Gojam) & 2090 & Open & White \\
\hline 43 & 215843 & Ethiopia (Gojam) & 2150 & Open & White \\
\hline 44 & 215844 & Ethiopia (Gojam) & 1800 & Open & White \\
\hline 45 & 215869 & Ethiopia (Gojam) & 2060 & Open & White \\
\hline 46 & 215870 & Ethiopia (Gojam) & 2170 & Open & White \\
\hline 47 & 215873 & Ethiopia (Gojam) & 2330 & Open & Dark \\
\hline 48 & 215874 & Ethiopia (Gojam) & 2350 & Open & Dark \\
\hline 49 & 215889 & Ethiopia (Gojam) & 2100 & Open & Red \\
\hline 50 & 215890 & Ethiopia (Gojam) & 2080 & Open & Brown \\
\hline 51 & 215891 & Ethiopia (Gojam) & 2070 & Open & Dark \\
\hline 52 & 215892 & Ethiopia (Gojam) & 2070 & Open & Dark \\
\hline 53 & 215916 & Ethiopia (Gojam) & 2100 & Open & White \\
\hline 54 & 215960 & Ethiopia (Gojam) & 1980 & Open & White \\
\hline 55 & 215961 & Ethiopia (Gonder) & 1940 & Open & White \\
\hline 56 & 215962 & Ethiopia (Gonder) & 2000 & Open & White \\
\hline 57 & 215963 & Ethiopia (Gonder) & 2000 & Open & White \\
\hline 58 & 215964 & Ethiopia (Gonder) & 1950 & Open & White \\
\hline 59 & 215966 & Ethiopia (Gonder) & 1880 & Open & Brown \\
\hline 60 & 215968 & Ethiopia (Gonder) & 2500 & Close & Red \\
\hline 61 & 215981 & Ethiopia (Gonder) & 1850 & Close & Red \\
\hline 62 & 215986 & Ethiopia (Gonder) & 2120 & Open & White \\
\hline 63 & KNE \# 1098 & Kenya & $\mathrm{Na}$ & Close & Red \\
\hline 64 & Bako local & Ethiopia (Wellega) & 1650 & Close & Red \\
\hline
\end{tabular}

${ }^{a} \mathrm{Na}=$ Not available 
Separate and pooled analyses of variance over location were made using the following models, respectively, as:

$$
\begin{gathered}
\rho_{\mathrm{ik}}=\mu+\mathrm{r}_{\mathrm{k}}+\mathrm{g}_{\mathrm{i}}+\mathrm{e}_{\mathrm{ik}} \\
\rho_{\mathrm{ijk}}=\mu+\mathrm{l}_{\mathrm{j}}+\mathrm{r}_{\mathrm{k}}+\mathrm{g}_{\mathrm{i}}+(\mathrm{gl})_{\mathrm{ij}}+\mathrm{e}_{\mathrm{ijk}}
\end{gathered}
$$

where $\rho_{\mathrm{ik}}\left(\rho_{\mathrm{ijk}}\right)=$ phenotypic observation on genotype $\mathrm{i}$ in replicate $\mathrm{k}$ (at location $\mathrm{j}$ ) $(\mathrm{i}=1 \ldots \mathrm{G}, \mathrm{j}=1 \ldots \mathrm{L}$, and $\mathrm{k}=$ $1 \ldots R$ ) and $G, L$ and $R=$ number of genotypes, location and replication, respectively, $\mu=$ grand mean, $r_{k}=$ the effect of replicate $k, g_{i}=$ the effect of genotype $i, l_{j}=$ the effect of location $\mathrm{j},(\mathrm{gl})_{\mathrm{ij}}=$ the interaction effect between genotype and location and $\mathrm{e}_{\mathrm{ik}}\left(\mathrm{e}_{\mathrm{ijk}}\right)=$ error.

Components due to genotype $\left(\sigma_{\mathrm{G}}^{2}\right)$, environment $\left(\sigma_{\mathrm{E}}^{2}\right)$, genotype by environment interaction $\left(\sigma_{\mathrm{GE}^{2}}\right)$ variances, and broad-sense heritability $\left(h^{2}\right)$ and the expected genetic gain from selection (GA) were calculated from the separate and pooled analyses of variance by assuming various observed mean squares equal to their expected mean squares as suggested in Singh and Chaudhary (1985).

Clustering of accessions was performed using the average linkage method of SAS software (SAS Institute, 1996). The pseudo $\mathrm{F}$ and the pseudo $\mathrm{t}^{2}$ statistics were examined to determine the optimum number of clusters. Standardized Mahalanobis's $\mathrm{D}^{2}$ statistics was used to determine genetic distance between clusters as one of the potent techniques of classification (Singh, 1990). This was calculated as:

$$
\mathrm{D}_{\mathrm{ij}}^{2}=(\mathrm{xi}-\mathrm{xj})^{\prime} \operatorname{cov}^{-1}(\mathrm{xi}-\mathrm{xj})
$$

where $\mathrm{D}^{2} \mathrm{ij}=$ the distance between cases $\mathrm{i}$ and $\mathrm{j}$; $\mathrm{xi}$ and $\mathrm{xj}=$ vectors of the values of the variables for cases $i$ and $j$; and $\operatorname{cov}^{-1}=$ the pooled within groups variance-covariance matrix.

The $\mathrm{D}^{2}$ values obtained for pairs of clusters were considered as the calculated values of Chi-square $\left(\mathrm{X}^{2}\right)$ and were tested for significance both at $1 \%$ and $5 \%$ probability levels against the tabulated value of $\mathrm{X}^{2}$ for ' $\mathrm{P}$ ' degree of freedom, where $\mathrm{P}$ is the number of characters considered as suggested by Singh and Chaudhary (1985).

\section{Results}

\subsection{Analysis of Variance}

The result obtained from analysis of variance for the traits studied at both locations showed that the mean squares due to genotype and genotype by location interaction were significant $(\mathrm{P} \leq 0.05)$ for all traits except the genotype by location interaction for number of fingers per main ear which was non-significant (Table 2). The significant mean squares among the genotypes for all the traits may indicate the presence of sufficient genetic differences among the materials studied for all the traits and the possibility to undertake cluster and distance analysis. Similarly, the significant mean squares for genotype by location interaction may depict the distinctness of the two locations or the differential responses of the genotypes to the locations or both as it is not only the nature of the test genotypes but also the degree of differences between the environments that influences the magnitude of genotype by

\begin{tabular}{|c|c|c|c|c|c|c|}
\hline \multirow[t]{2}{*}{ Trait } & \multicolumn{2}{|c|}{ Arsi Negele ${ }^{a}$} & \multicolumn{2}{|c|}{ Bako } & \multicolumn{2}{|c|}{ Genotype x Location } \\
\hline & MS (63) & $\mathrm{CV}(\%)$ & MS (63) & $\mathrm{CV}(\%)$ & MS (63) & $\mathrm{CV}(\%)$ \\
\hline Days to flowering & $205.37^{*}$ & 4.45 & $99.09^{*}$ & 4.51 & $110.95^{*}$ & 4.48 \\
\hline Days to maturity & $227.06^{*}$ & 3.30 & $42.93^{*}$ & 2.49 & $66.57^{*}$ & 2.98 \\
\hline Plant height & $432.01^{*}$ & 10.80 & $278.04^{*}$ & 10.52 & $49.64^{*}$ & 1.70 \\
\hline Productive tillers plant ${ }^{-1}$ & $1316.75^{*}$ & 18.52 & $297.98^{*}$ & 20.60 & $216.48^{*}$ & 19.65 \\
\hline Ear length & $18.24^{*}$ & 11.35 & $17.08^{*}$ & 15.09 & $1.898^{*}$ & 13.31 \\
\hline Fingers main ear-1 & $5.00^{*}$ & 15.29 & $5.25^{*}$ & 15.26 & $1.43 \mathrm{NS}$ & 15.29 \\
\hline Ear weight plant ${ }^{-1}$ & $4487.70^{*}$ & 13.01 & $1688.50^{*}$ & 18.01 & $465.63^{*}$ & 14.95 \\
\hline Biomass plant ${ }^{-1}$ & $14811.30^{*}$ & 16.18 & $4491.12^{*}$ & 23.47 & $2553.97^{*}$ & 18.90 \\
\hline Grain weight plant ${ }^{-1}$ & $2167.90^{*}$ & 14.47 & $835.96^{*}$ & 23.07 & $235.12^{*}$ & 17.65 \\
\hline 1000 seeds weight & $0.64^{*}$ & 12.83 & $0.26^{*}$ & 14.66 & $0.29^{*}$ & 13.65 \\
\hline Harvest index & $0.02^{*}$ & 21.08 & $0.01^{*}$ & 14.90 & $0.01^{*}$ & 14.90 \\
\hline
\end{tabular}
environment interaction.

Table 2. Estimates of mean square and coefficient of variation of morpho-agronomic characters in finger millet.

\subsection{Heritability and Genetic Advance}

Broad-sense heritability values from separate analysis of variance at each location and pooled analysis across locations were higher $(>80 \%)$ for most of the characters, indicating the existence of a wealth of genetic variability among the population including for economic traits like grain yield (Table 3). Relatively lower heritability values of less than $70 \%$ were recorded for a few traits like harvest index, days to flowering and maturity and 1000 seed weight only in a few cases. High genetic advance values were also recorded for traits like productive tillers per plant, biomass per plant, ear length and ear weight per plant at both locations. Genetic gain from selection depends on the extent of variation and the magnitude of the heritable portion of this variation. Therefore, having such higher heritability values, making genetic progresses from selection would be possible for most of the traits studied. According to Singh (1990), if heritability of a trait is very high, say $80 \%$ or more, selection for such a trait should fairly be easy and successful. This is because there would be a close correspondence between genotype and phenotype due to a relatively smaller contribution of environment to the 
phenotype. But selection could be difficult or virtually impossible for a trait with low heritability, say less than $40 \%$, genotypic effects. due to the masking effect of the environment on the

Table 3. Estimates of heritability in broad sense $\left(\mathrm{H}^{2}\right)$ and genetic advance (GA) for the traits studied at Arsi Negele, Bako and across both locations.

\begin{tabular}{|c|c|c|c|c|c|c|}
\hline \multirow[t]{2}{*}{ Parameters } & \multicolumn{3}{|c|}{$\mathrm{H}^{2}$} & \multicolumn{3}{|c|}{ GA } \\
\hline & Arsi Negele & Bako & Across location & Arsi Negele & Bako & Across location \\
\hline Days to flowering & 92.6 & 85.9 & 42.7 & 15.8 & 10.2 & 5.0 \\
\hline Days to maturity & 86.4 & 89.4 & 67.3 & 15.5 & 12.0 & 8.1 \\
\hline Plant height & 90.5 & 89.4 & 92.5 & 22.4 & 18.0 & 20.0 \\
\hline Productive tillers plant ${ }^{-1}$ & 95.1 & 89.9 & 84.5 & 41.1 & 18.4 & 26.6 \\
\hline Ear length & 95.3 & 91.6 & 94.4 & 4.8 & 4.5 & 4.1 \\
\hline Fingers main ear ${ }^{-1}$ & 67.9 & 73.4 & 83.7 & 2.6 & 2.0 & 2.1 \\
\hline Ear weight plant ${ }^{-1}$ & 93.6 & 88.1 & 91.8 & 74.6 & 43.0 & 58.4 \\
\hline Biomass plant ${ }^{-1}$ & 91.8 & 81.6 & 84.7 & 132.8 & 65.1 & 92.2 \\
\hline Grain weight plant ${ }^{-1}$ & 91.4 & 80.9 & 91.5 & 50.6 & 27.8 & 40.5 \\
\hline 1000 seeds weight & 81.7 & 69.3 & 51.7 & 0.7 & 0.42 & 0.3 \\
\hline Harvest index & 66.7 & 50.0 & 65.2 & 0.1 & 0.04 & 0.04 \\
\hline
\end{tabular}

\subsection{Cluster and Distance Analyses}

The accessions were grouped into four diversity classes (Table 4). Cluster II was the largest with 39 accessions or constituting closer to $61 \%$ of the total population followed by cluster I with 22 accessions or close to $34 \%$ of the total population. Cluster III constituted 2 accessions while cluster IV had only one accession. The hierarchy of relatedness among the accessions is given in Figure 1, showing the hierarchal distances of each population to all other populations.

The generalized pair wise squared distances $\left(D^{2}\right)$ among the four clusters is presented in Table 5. The maximum distance was found between cluster I and IV ( $\left(\mathrm{D}^{2}=22529\right)$. The second most divergent clusters were cluster II and IV $\left(\mathrm{D}^{2}=22211\right)$. The genetic divergence between clusters III and IV $\left(\mathrm{D}^{2}=21737\right)$ and between I and III were also highly significant $(\mathrm{P}<0.01)$. The distance between clusters II and III was non-significant, suggesting close relationship among the accessions. Within cluster distances are expected to be smaller than any of between clusters distances as a member of the same cluster are assumed related with each other in terms of the traits under consideration.

The cluster means estimated over accessions for the eleven characters clearly revealed the presence of considerable inter-cluster differences. Accordingly, cluster I had the lowest score for most of the traits considered while cluster II contained accessions with the highest score characterized by best performance for all traits and late maturing accessions while clusters III and IV had intermediate accessions for most of the traits including yielding potential and maturity period (Table 6).

Table 4. Grouping of 64 millet genotypes into different clusters.

\begin{tabular}{|c|c|c|c|}
\hline Cluster & No. of accessions & Accession number & Origin \\
\hline \multirow[t]{3}{*}{$\mathrm{I}$} & \multirow[t]{3}{*}{22} & $\begin{array}{l}\text { 2203058, 203060, 100009, 100059, 100016, 100008, 203061, } \\
\text { 215968, 215981 }\end{array}$ & Ethiopia \\
\hline & & $\begin{array}{l}203260,203303,203264,203289,203265,203288,203309, \\
203251,203300,203260,203391,203278\end{array}$ & Zimbabwe \\
\hline & & KNE \# 1098 & Kenya \\
\hline \multirow[t]{2}{*}{ II } & \multirow[t]{2}{*}{39} & $\begin{array}{l}100010,100006,100058,100043,203057,100057,100019, \\
100064,100015,100050,212692,205837,205838,215839, \\
215841,215842,215843,215844,215869,215870,215873, \\
215874,215889,215890,215891,215892,215916,215960, \\
215961,215962,215963,215964,215986, \text { Bako local }\end{array}$ & Ethiopia \\
\hline & & $203246,203259,203319,203258,203246$ & Zimbabwe \\
\hline III & 2 & 100004,215966 & Ethiopia \\
\hline IV & 1 & 100014 & Ethiopia \\
\hline
\end{tabular}


Distance

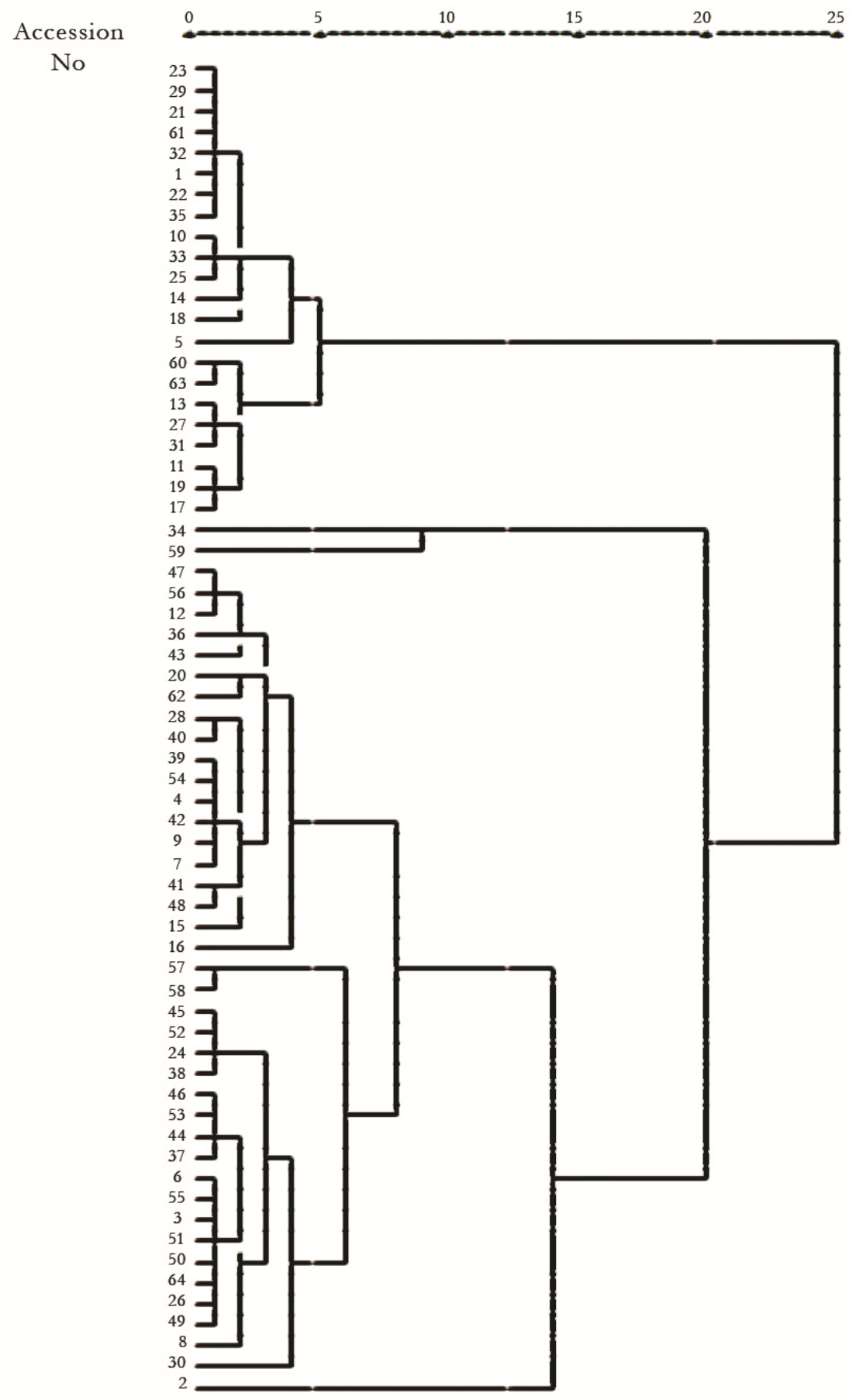

Figure 1. Dendrogram of 64 locally collected and introduced millet accessions based on based on average linkage hierarchical cluster analysis between groups.

\subsection{Principal Component Analysis}

The first three principal components accounted for close to $73 \%$ of the total variation, of which close to $50 \%$ was contributed by the first and $13 \%$ by the second principal components (data not shown). The result indicates that most of the characters individually contributed small effects $( \pm 0.07$ to 0.40$)$ to the total variation and thus the assignment of accessions to different clusters was largely the result of cumulative effects of a number of characters. However, certain characters with relatively higher weights in the first principal component like ear weight, biomass weight and grain weight had relatively larger contribution to the total diversity and clustering of the accessions into different groups. 
Table 5. Pair wise generalized squared distances $\left(\mathrm{D}^{2}\right)$ among the four clusters (I-IV) comprising 64 finger millet accessions.

\begin{tabular}{llrrr}
\hline Cluster & I & II & III & IV \\
\hline I & 0 & $22^{*}$ & $70^{* *}$ & $22529^{* *}$ \\
II & 0 & 19 & $22211^{* *}$ \\
III & & 0 & $21737^{* *}$ \\
IV & & & 0 \\
\hline
\end{tabular}

* = Significant at $p<0.05 ; * *=$ Significant at $p<0.01$

Table 6. Cluster means for eleven characters used to classify finger millet accessions.

\begin{tabular}{|c|c|c|c|c|c|}
\hline \multirow[b]{2}{*}{ Trait } & \multicolumn{4}{|c|}{ Cluster } & \multirow[b]{2}{*}{ Grand mean } \\
\hline & I & II & III & IV & \\
\hline Days to flowering & 81.43 & 157.04 & 88.00 & 82.50 & 102.24 \\
\hline Days to maturity & 153.36 & 290.38 & 160.25 & 165.00 & 192.25 \\
\hline Plant height $(\mathrm{cm})$ & 45.46 & 108.56 & 72.50 & 60.80 & 71.83 \\
\hline Productive tillers plant ${ }^{-1}$ & 21.27 & 75.84 & 54.15 & 40.70 & 47.99 \\
\hline Ear length $(\mathrm{cm})$ & 5.73 & 16.68 & 9.85 & 11.00 & 10.82 \\
\hline No. of fingers main ear ${ }^{-1}$ & 7.52 & 14.81 & 8.60 & 10.00 & 10.23 \\
\hline Ear weight plant ${ }^{-1}(\mathrm{~g})$ & 68.34 & 220.06 & 155.10 & 122.70 & 141.55 \\
\hline Biomass weight plant ${ }^{-1}(\mathrm{~g})$ & 105.24 & 347.16 & 279.15 & 194.50 & 231.51 \\
\hline Grain weight plant ${ }^{-1}(\mathrm{~g})$ & 51.89 & 158.25 & 100.20 & 88.30 & 99.66 \\
\hline 1000 seeds weight $(\mathrm{g})$ & 2.72 & 3.82 & 2.30 & 2.05 & 2.72 \\
\hline Harvest index & 0.46 & 0.81 & 0.36 & 0.42 & 0.51 \\
\hline
\end{tabular}

\section{Discussion}

Owing to micro-evolutionary factors, populations geographically separated for substantial period of time are naturally expected to be genetically distant from one another when compared with populations subjected to same environmental pressure (Chandel and Joshi, 1983). However, in the present case, the distribution of accessions into different clusters did not follow the difference in geographical origin of accessions. Accessions from Zimbabwe were grouped with those from Ethiopia regardless of geographic origin. Several possible reasons could be given for this. The materials might initially share common origin or selection might have taken place for traits of common interest in both countries like agronomic adaptations, yield components and other traits of agronomic importance included in this study. Early reports in other crops from Ethiopia and elsewhere support also this finding (Ford-Lloyd and Jackson, 1986; Demissie and Bj申rnstad, 1997; Nigussie, 2001). It is possible that diversity in germplasm collections may or may not be uniformly distributed across eco-geographic regions depending on agricultural practices and ecological and socio-economic factors (Singh, 1990; Chahal and Gosal, 2002). Therefore, selection of parents for hybridization for developing breeding populations need not necessarily be based on geographic origin provided that sufficient diversity exists within a particular origin.

This study clearly revealed that there was high genetic diversity within and between the local and exotic finger millet germplasm collections. Previous reports also indicated the existence of considerable diversity among collections from Africa in general (Kempanna and Govimdu, 1969) and Ethiopia in particular (Yilma and Abebe, 1986). Maximum genetic recombination and variation in the subsequent generation is expected from crosses that involve parents generated from the clusters exhibited maximum genetic distances. Crosses between selections from cluster IV with selections from all other clusters are, therefore, expected to provide relatively better genetic recombination or heterotic hybrids and maximum segregation in their progenies. However, the selection of parents should also consider the special advantages of each cluster and each accession within a cluster depending on the specific objectives of hybridization as suggested by others (Singh, 1990; Chahal and Gosal, 2002). In addition to genetic diversity, parents should express the optimum level of all the desired component traits for accumulating yield, should be resistant to biotic and abiotic environmental stresses and they should fulfill quality parameters required in the target area (Singh, 1990; Wallace and Yan, 1998).

\section{Conclusions}

There is high genetic diversity in the Ethiopian and Zimbabwean millet accessions even though it was not uniformly distributed across the regions. From the present study it was apparent that overlapping in clustering pattern might be possible among accessions from different regions that might be closely related. Similarly accessions from the same regions but with different genetic background might fall into different clusters implying the absence of definite correspondence between geographic origin and genetic diversity. Parental selection should, therefore, not be based on geographic 
difference but it should rather be made based on systematic assessment of genetic diversity within and between populations. Future collection and conservation missions and breeding programs should focus on effective exploitation of not only inter-regional diversity but also intra-regional diversity in the species. Intercluster gene recombination of sample accessions drawn from the significantly distant clusters followed by selection should prove to generate agronomically desirable progenies as expected. However, parental selection should be based not only on the level of genetic diversity but also on traits of interest in the given domain.

\section{Acknowledgements}

The authors are grateful to Mr. Mussa Jarso of the Ethiopian Institute of Agricultural Research (EIAR), Holetta Research Center, for his assistance in analyses of the data.

\section{References}

Chahal, G.S. and Gosal, S.S. 2002. Principles and Procedures of Plant Breeding: Biotechnological and Conventional Approaches. Narosa Publishing House, New Delhi.

Chandel, K.P.S. and Joshi, B.S. 1983. Multivariate analysis in green-seeded pea. Indian Journal of Agricultural Science. 53 (4): 198-200.

Demissie, A. and Bjфrnstad, A. 1997. Geographical, altitude and agro-ecological differentiation of isozyme and hordein genotypes of landrace barleys from Ethiopia: Implications to germplasm conservation. Germplasm Collections and Crop Evolution 44: 43-55.

Dogget, H. 1986. Small millet: A selective review. In: Seetharam, A., Reley, K.W. and Harinarayana, G. (eds.). Small millet in Global Agriculture. Proceeding of the First International Small Millet Workshop. 29 October-2 November 1986. Bangalore, India. pp. 1-17.

FAO (Food and Agriculture Organization). 1998. The State of World Plant Genetic Resource for Food Agriculture. FAO Publication. Rome.
Ford-Lloyd, B. and Jackson, M. 1986. Plant Germplasm Collections: An Introduction to Their Conservation and Use. Edward Arnold, Australia.

Kempanna, C. and Govimdu, H.C. 1969. Pattern of phenotypic variation in African collection of finger millted [Eleusine coracana (L) Gaertn]. Mysore Agriculture Journal 3: 299-305.

Nigussie, A. 2001. Germplasm Diversity and Genetics of Quality and Agronomic Traits in Ethiopian Mustard (Brassica carinata A. Braun). Doctoral Dissertation, Georg-August University of Göttingen, Germany.

Pulseglove, J.W. 1988. Tropical Crops: Monocotyledons. Longman Group Limited, England.

SAS (Statistical Analysis System). 1996. SAS/STAT Guide for Personal Computers, Version 6.12 Edition. Cary, NC: SAS Institute Inc.

Singh, B.D. 1990. Plant Breeding: Principles and Methods. Kalyani Publishers, New Delhi-Ludhiana.

Singh, R.K. and Chaudhary, B.D. 1985. Biometrical Methods in Quantitative Genetic Analysis. Kalyani Publishers, New Delhi-Ludhiana.

Tadessie, M., Aberra, D., Zenbaba, G. and Erenso, D. 1995. Finger millet [Eleusine coracana (L) Gaertn]: A potential crop in Ethiopia. In: Samwiri, Z.M. and Gebisa, E. (eds.). Proceedings of a Workshop Organized to Reestablish Sorghum and Millet in Eastern and Central Africa. 6-9 November 1995. Kampala, Uganda. pp. 193-197.

Wallace, D.H. and Yan, W. 1998. Plant Breeding and WholeSystem Crop Physiology: Improving Crop Maturity, Adaptation and Yield. University Press, Cambridge, UK.

Yilma, K. and Abebe, M. 1986. Improvement of finger millet in Ethiopia. In: Seetharam, A., Reley, K.W. and Harinarayana, G. (eds.). Small Millet in Global Agriculture. Proceedings of the First International Small Millet Workshop. 29 October-2 November 1986. Bangalore, India. pp. 173-176. 